Didáctica Geográfica n 21, 2020,pp. 203-225

DOI: https://doi.org/10.21138/DG.547

ISSN electrónico: 2174-6451

\title{
LA ENSEÑANZA DE LA GEOGRAFÍA EN TIEMPOS DE CORONAVIRUS: PERCEPCIÓN DE LA COMUNIDAD EDUCATIVA
}

GEOGRAPHY TEACHING IN TIME OF CORONAVIRUS: PERCEPTION OF THE EDUCATIONAL COMMUNITY

\section{L'ENSEIGNEMENT DE LA GÉOGRAPHIE À L'ÉPOQUE DU CORONAVIRUS: PERCEPTION DE LA COMMUNAUTÉ ÉDUCATIVE}

José Ángel Llorente-Adán

Universidad de La Rioja.

jose-angel.llorente@unirioja.es

Recibido: 31/05/2020

Aceptado 22/09/2020

\section{RESUMEN:}

El presente trabajo se enmarca en la situación actual generada en el sistema educativo por la crisis sanitaria causada por la pandemia del coronavirus a lo largo de los últimos meses del curso 2019-2020. El objetivo fundamental es analizar las primeras consecuencias que ha supuesto el cambio repentino e inesperado para la comunidad educativa, a nivel general, así como las repercusiones que se hayan podido generar en cuanto a la enseñanza y el aprendizaje de la geografía, a nivel particular. Para alcanzar este propósito se ha llevado a cabo un cuestionario que ha sido completado por 547 personas de toda España que forman parte de la comunidad educativa. Las conclusiones extraídas permiten conocer las transformaciones que se hayan podido dar tanto en el 
sistema de enseñanza-aprendizaje como en la docencia y adquisición de contenidos geográficos al pasar de un sistema presencial a una docencia a distancia.

\section{Palabras clave:}

Didáctica de la geografía; sistema de enseñanza-aprendizaje; comunidad educativa; propuestas educativas; virus COVID-19.

\section{Abstract:}

This work is part of the current situation generated in the educational system because of the health crisis caused by the coronavirus pandemic, throughout the last months of the 2019-2020 academic year. The main objective is to analyze the first consequences that the sudden and unexpected change has entailed for the educational community in general, as well as the repercussions that this situation may have generated in terms of teaching and learning Geography in particular. To achieve this purpose, we have made a questionnaire that has been completed by 547 people from all over Spain who are part of the educational community. The conclusions allow us to know the transformations that may have taken place both in the general teaching-learning system, as well as in the specific teaching and acquisition of geographic knowledges when moving from a face-to-face system to a distance teaching.

\section{KEYWORDS:}

Geography teaching; teaching-learning system; educational community; didactic proposals; virus COVID-19.

\section{RÉSUMÉ :}

Cet article s'inscrive dans la situation actuelle générée dans le système éducatif par la crise sanitaire provoquée par la pandémie de coronavirus, tout au long des derniers mois de l'année académique 2019-2020. L'objectif principal est celui d'analyser les premières conséquences du changement soudain et inattendu pour la communauté éducative en général, ainsi que les répercussions que cette situation a pu générer dans l'enseignement et l'apprentissage de la Géographie en particulier. Pour atteindre cet objectif, on a fait un questionnaire qui a été rempli par 547 personnes de toute l'Espagne qui font partie de la communauté éducative. Les conclusions tirées permettent de connaître les transformations qui ont pu s'opérer en même temps dans le système d'enseignement-apprentissage de façon général, ainsi que, plus spécifiquement, dans l'enseignement et l'acquisition de contenus géographiques lors du passage d'un système en face à face à un enseignement à distance.

\section{MOTS-CLÉS:}

Enseignement de la Géographie; système d'enseignement-apprentissage; communauté éducative; propositions didactiques; virus COVID-19. 


\section{INTRODUCCIÓN}

Entre las últimas semanas de 2019 y el primer semestre de 2020 el mundo asistió a la propagación de un virus que ha supuesto todo un reto para la comunidad científica y que obligó a que, progresivamente, se confinasen más de 4.500 millones de personas de unos 180 países del planeta. Se trataba de la primera pandemia del siglo XXI cuyo primer antídoto, al menos inicialmente, ha sido el aislamiento social de más de la mitad de la población mundial (Romero y Ordáz, 2020). Según la UNESCO (2020 a), un total de más de 1.184.126.508 estudiantes de todo el mundo se han visto afectados por los cierres de las aulas. Esto supone el 67,6\% del total del alumnado matriculado. De ellos, 7.996.895 son españoles.

En España, el primer caso de persona contagiada se identificó a finales del mes de enero. A partir de entonces el virus comenzó a propagarse hasta alcanzar la amenaza nacional en la que se convirtió a mediados de marzo. En lo que a cambios drásticos supone para la comunidad educativa de nuestro país, se puede decir que todo comenzó el 14 de marzo, cuando el Gobierno decretó el estado de alarma para la gestión de la situación generada por la crisis sanitaria de la COVID-19 (Real Decreto 463/2020). Era entonces cuando se suspendían las clases de manera oficial para todo el estado, aunque en comunidades como Madrid, La Rioja y el País Vasco ya lo habían hecho a lo largo de esa semana, por ser foco de inicio en la propagación del coronavirus en nuestro país (El País, 12 marzo 2020). Esta drástica medida, que en principio fue temporal, se prolongó hasta final de curso.

Entre la incredulidad de una parte de la población, el desconcierto y la incertidumbre de otra, la suspensión de las clases, inicialmente, fue asumida por la mayoría de los estudiantes como unos días de parón casi a modo de vacaciones, aunque en pocos días el desencadenamiento de los hechos hizo que la población tomase conciencia de la relevancia del momento crítico que se vivía, sin tiempo de adaptación.

Evidentemente, el paso del tiempo reconsiderará lo trascendental de los momentos vividos esas semanas, cuando la población pasó de la normalidad a la irrupción del confinamiento. Fueron semanas de adaptación, de cambios de hábitos sociales, familiares, laborales, de atajamiento de órdenes estatales por el bien común que afectaron a todas las escalas de la vida. Lógicamente, estas transformaciones también dejaron huella en el sistema de enseñanza-aprendizaje y en la comunidad educativa, como se analizará en este trabajo (Cabrera, 2020; Cotino Hueso, 2020; Nin, Acosta y Leduc, 2020).

Desde las últimas décadas del pasado siglo, uno de los cambios que se han producido en la sociedad española responde precisamente a transformaciones en su sociabilización. De acuerdo con Loureiro Nunes y Spinelli Braga (2012), con el paso de una sociedad rural a una urbana, de una sociedad con un núcleo familiar menos compactado, la socialización primaria que antes, generalmente, partía del seno familiar progresivamente se ha ido 
trasladando a la escuela. De tal manera que, es el propio sistema educativo el que debe cubrir esta ausencia y al que se le solicita un mayor desarrollo en la formación integral del individuo. Un hecho que va más allá del aprendizaje de contenidos teóricos de cada materia. Por todo ello, el sistema escolar ha ido asumiendo una responsabilidad creciente sobre la formación de los jóvenes como personas cívicas y respetuosas con las normas de convivencia establecidas en la propia sociedad. Todo esto, como tantas otras situaciones, se ha cuestionado cuando los alumnos han dejado de ir a colegios, institutos y universidades de manera presencial para permanecer en casa de forma continuada durante semanas. Era el paso de un sistema de enseñanza-aprendizaje presencial a un sistema online.

Hace una década, autores como Jurado Gómez (2009), afirmaban que las madres y padres podían participar del sistema educativo de manera activa allí donde se facilitase la participación de los progenitores en la propia comunidad educativa. La situación vivida por el confinamiento obligatorio ha hecho, no obstante, que las familias asuman este rol que antes no tenían.

Además de los cambios profundos generados en el sistema escolar, durante estos meses de crisis sanitaria, profesionales, administraciones y los propios implicados, los integrantes de la comunidad educativa, han abierto un debate sobre las ventajas y debilidades de un sistema educativo presencial o a distancia.

Evidentemente, aspectos como la convivencia entre personas y los lazos de unión que esta implica salen reforzados en un sistema educativo presencial (Del Rey, OrtegaRuiz y Feria, 2009), frente a la individualidad que, con frecuencia, supone el sistema de enseñanza-aprendizaje a distancia. Por otro lado, la enseñanza y el aprendizaje online también cuentan con muchos adeptos, por el propio desarrollo progresivo de los recursos digitales, cada vez más variados y mejor configurados o por el esfuerzo en impulsar estrategias para incentivar el aprendizaje colaborativo, la creación de comunidades de enseñanza y aprendizaje virtuales, etc. entre los mismos participantes de la formación a distancia (Scagnoli, 2005)

Un aspecto positivo del sistema educativo presencial es la importancia de la convivencia en el día a día y que redunda en la formación como ciudadanos y ciudadanas del propio alumnado. Generalmente, cuando se alude a la situación de convivencia en un grupo de clase, dentro del propio centro escolar, suele ser porque se está produciendo una mala convivencia, mientras que si esta es buena pocas veces se saca a colación, por lo que, con frecuencia, el tratamiento de la convivencia adquiere tintes negativos (Del Rey, OrtegaRuiz y Feria, 2009). A este respecto, el propio conocimiento geográfico tiene mucho que decir como ciencia social que es. De acuerdo con De Miguel (2012), la Geografía es una materia de estudio que favorece la adquisición de la competencia social, además de fomentar la madurez y la formación integral de los propios alumnos dentro del ejercicio tanto de sus derechos como de sus deberes con respecto a la vida en sociedad. 
La cuestión del desarrollo de habilidades sociales en discentes, especialmente los adolescentes, se puede ver afectada si la situación actual de aislamiento social continuase en el tiempo. De hecho, de acuerdo con Ruiz Conesa (2019), la interacción social se entiende como objeto y medio de aprendizaje dentro del sistema de enseñanza-aprendizaje.En estos momentos, a finales del mes de mayo, todos estos planteamientos son solo interrogantes y se encuentran en pleno debate. Durante la desescalada y los meses de verano se trató sobre cómo sería el regreso a las aulas: presencial, semipresencial o a distancia (Zafra, 2020). Aunque, en este aspecto, en la mayor parte de los casos se esperó hasta el último momento para tomar decisiones definitivas, sin demasiado consenso o análisis previo. La mayor parte de las comunidades autónomas ha pretendido la enseñanza presencial para los niveles educativos de primaria y secundaria. En algunas ocasiones con el objetivo de cumplir con la separación de metro y medio entre cada alumno sumado a la falta de espacio físico de los centros se optó por un sistema semipresencial como se ha hecho en algunos cursos de secundaria. Respecto a las universidades, cada equipo rectoral ha tomado sus propias decisiones. Algunas han optado por la presencialidad absoluta, otras por la docencia on line desde el inicio del curso, otras reservan la presencialidad solo para las materias con clases prácticas. Incluso en algunos campus, la elección la han dejado en manos de cada Facultad, por lo que en una misma universidad se está desarrollando un sistema de enseñanza on line y presencial al mismo tiempo. En este sentido se echa en falta decisiones más consensuadas y realistas. Ya que, por ejemplo, algunas universidades anunciaban una presencialidad al 100\% durante los meses de verano con el propósito de no perder matriculados, para finalmente llevar a cabo un sistema a distancia desde comienzos del curso.

En lo que respecta a la situación de la Geografía en el sistema de enseñanzaaprendizaje, un paso previo en la toma de medidas acertadas puede ser conocer el papel del conocimiento geográfico respecto a la situación de la comunidad educativa y lo que consideran sus principales integrantes: alumnado, profesorado y madres y padres, tal y como se verá a continuación.

\section{OBJETIVOS Y JUSTIFICACIÓN}

Entre los objetivos de este trabajo de investigación está el conocer el conjunto de consecuencias derivadas de la transformación en el sistema educativo comprendido entre la secundaria y hasta los estudios universitarios, al pasar de una docencia cien por cien presencial, o con un alto grado de presencialidad, a un sistema de enseñanza-aprendizaje totalmente a distancia. Por este motivo, como entre las pretensiones estaba el conocer la opinión de la comunidad educativa sobre todas estas transformaciones, se pensó en un cuestionario como medio de poder implicar, de manera directa y a nivel nacional, 
a los principales protagonistas que conforman dicha comunidad educativa: alumnado, profesorado y padres, entre otros.

Para ello se ha contado con la colaboración desinteresada de aproximadamente 550 personas, entre estudiantes, profesores y progenitores, que han realizado el formulario preparado a tal efecto. Como se verá más adelante, el sondeo abarcaba desde asuntos genéricos del sistema de enseñanza-aprendizaje, como la situación personal atravesada durante estos meses de confinamiento y alerta sanitaria, hasta cuestiones concretas relacionadas con la enseñanza y el aprendizaje de los contenidos geográficos.

El objetivo es estudiar el cambio del sistema de enseñanza-aprendizaje presencial a distancia y sus posibles repercusiones en el saber geográfico, con el fin de dar a conocer sus debilidades o fortalezas para que sirva de punto de partida a partir del cual poder establecer estrategias que se adapten a las circunstancias y mejoren la didáctica de la geografía.

\section{METODOLOGÍA}

Para contextualizar este trabajo dentro del campo de estudio de la didáctica de la geografía se han realizado las habituales labores de recopilación de información y estudio bibliográfico dentro del propio ámbito científico.

Al mismo tiempo, con el fin de cumplir con los objetivos marcados de analizar la situación actual por la que está pasando la comunidad educativa y conocer de primera mano su estado durante esta primavera inusual, en abril se elaboró un cuestionario cuyo sondeo se realizó a lo largo del mes de mayo, durante sus tres primeras semanas. Se hicieron auténticos esfuerzos por llegar a un número máximo de destinatarios cuyo nexo era ser parte integrante de la comunidad educativa y, más en concreto, estar vinculado a la propia geografía, bien como docente o bien como alumno. Además de a los propios progenitores, que en el caso del alumnado de niveles educativos preuniversitarios han adquirido un gran protagonismo con la educación a distancia, como se demostrará más adelante. De esta manera, se procedió a enviar los cuestionarios a buena parte de los centros educativos de secundaria de nuestro país, a través de los distintos buscadores de las diferentes comunidades autónomas o a nivel nacional, como, por ejemplo, el Registro Estatal de Centros no Universitarios (RCD) (Ministerio de Educación, Cultura y Deporte, 2020), así como al conjunto de Universidades españolas que imparten geografía en sus distintas variantes: Grado en Geografía; Grado en Geografía e Historia; Grado en Geografía y Ordenación del Territorio; Grado en Geografía y Medio Ambiente; Grado en Geografía, Desarrollo Territorial y Sostenibilidad; Grado en Geografía, Medio Ambiente y Planificación Territorial; Grado en Geografía y Gestión del Territorio; Grado en Geografía, Ordenación del Territorio y Gestión del Medio Ambiente; Grado en Geografía, Análisis Territorial y Sostenibilidad; Grado en Historia, Geografía e 
Historia del Arte; Grado en Historia y Geografía (Ministerio de Ciencia, Innovación y Universidades, 2020). Además, a los esfuerzos de difusión, se sumaron desde el primer momento que se les solicitó tanto el Grupo de trabajo de Didáctica de la Geografía como la propia Asociación Española de Geógrafos (AGE), que difundió el formulario a través de su página oficial de Internet (AGE, 2020). Pero, además de contactar con centros de educación de secundaria y universitarios, el sondeo se dirigió a varias decenas de asociaciones de madres y padres de alumnos (AMPAS) de distintos puntos de España. De tal modo que la encuesta principal fue la base de tres cuestionarios que se adaptaron según fuese su destinatario: el alumnado, el profesorado o los progenitores de los estudiantes. Es decir, una gran parte del formulario era común para toda la comunidad educativa mientras que, al mismo tiempo, cada uno contaba con una parte específica.

Se debe entender que alcanzar las 547 supuso una gran tarea de difusión. El hecho de promover la expansión de los cuestionarios para que se tuviese una muestra lo más amplia y representativa posible, hizo comprobar que el nivel de respuesta de participación era bajo. De ahí que se reforzasen esfuerzos en su difusión. La explicación de dicho nivel de respuesta puede ser el contexto temporal en el que se realizó, en pleno estado de alarma, justo al inicio de la fase de desescalada, ya en la recta final del curso, y con todo el trabajo añadido que ha supuesto la docencia a distancia. Por otro lado, la representatividad geográfica de la encuesta se ha conseguido al tener participantes procedentes de cuarenta y una de las cincuenta provincias españolas.

Como se ha explicado, el sondeo consistió en tres cuestionarios realizados con la aplicación de Microsoft Office 365, Forms. Una herramienta que permite realizar formularios de manera digital. Desde el primer momento se configuró para que fuese anónimo, aunque, eso sí, pretendiendo tener al menos alguna característica de cada individuo como el sexo y la edad, el nivel de estudios que se estaba cursando o en el que se impartía, la titularidad del centro (público, concertado o privado) y su identificación. Posteriormente, el sondeo lo completaban dos bloques de preguntas. El primero se centraba en la transformación de una enseñanza-aprendizaje presencial a un modelo a distancia con la crisis sanitaria del coronavirus (COVID-19). Este comprendía desde cuestiones relacionadas con sensaciones personales vividas a valoraciones sobre la manera de actuar de cada uno de los integrantes de la comunidad educativa. El segundo bloque se fundamentaba en el contenido geográfico y en aspectos de su sistema de enseñanzaaprendizaje que pudiesen haberse visto afectados durante los últimos meses del curso.

Se debe indicar además que algunas partes del propio cuestionario, como las asociadas al bloque de Geografía, contaban con bifurcaciones, es decir, dependiendo del nivel de estudios que estuviese cursando el alumno que realizaba el formulario le aparecía una pregunta u otra. Así, por ejemplo, si era un universitario, este debía responder a preguntas relacionadas con Sistemas de Información Geográfica (SIG), mientras que, 
si eran estudiantes de educación secundaria obligatoria o de bachillerato, estos tenían que valorar el aumento del grado de dificultad de ciertas asignaturas, entre ellas las de contenido espacial como 'Ciencias Sociales', 'Geografía e Historia' o 'Geografía'. Es decir, las materias y/o asignaturas fundamentales con contenido geográfico de acuerdo con la ley educativa vigente según el Real Decreto 126/2014, que establece el currículo básico de la Educación Primaria, y el Real Decreto 1105/2014 dedicado a la Educación Secundaria Obligatoria y Bachillerato.

El sondeo alcanzó las 587 respuestas, de las que se descartaron unas cuarenta, aquellas que se consideraron que estaban realizadas sin el suficiente interés, sin implicación o sin reflexión al responderse en un tiempo mínimo inferior a cuatro minutos, y, por lo tanto, pudiesen resultar fraudulentas para la obtención de resultados. El tiempo medio de respuesta ha sido de 14 minutos aproximadamente. Como el objetivo de este trabajo es conocer la situación y la opinión de los grupos que forman la comunidad educativa (alumnos, profesores y padres), e investigar sobre su visión de la situación del momento en plena crisis sanitaria, el cuestionario se realizó durante las tres primeras semanas de mayo, cuando España seguía aún en "Estado de alarma", en concreto en su progresiva desescalada. Precisamente en un momento en el que el desconfinamiento estaba marcado por fases en las que se iba avanzando a distinta velocidad, según territorios, antes de comenzar a adaptarse a la nueva normalidad marcada por el distanciamiento social. Con respecto al proceso de tabulación o recuento de los datos obtenidos en los cuestionarios, la propia aplicación de Forms permite ver el reparto de porcentajes de manera directa o descargarlos en Excel para su elaboración y análisis, tal y como se realizó.

El número de encuestas respondidas tanto por alumnos como por profesores ha sido muy similar, de 260 y 247 respectivamente. Por su parte, han sido cuarenta cuestionarios recibidos de madres y padres. A continuación, pasamos a describir los resultados recogidos según cada grupo integrante de la comunidad educativa.

\section{RESULTADOS}

Como ya se ha indicado, los resultados obtenidos proceden de los cuestionarios cumplimentados entre docentes y alumnos de distintos niveles educativos a partir de Secundaria. Se ha descartado la educación Primaria porque la propia encuesta resultaba compleja para el alumnado de esta etapa. Y, de igual manera, no se ha difundido entre sus maestros puesto que tienen una formación generalista y no están tan vinculados con la Geografía como el resto de los docentes especializados en ella. Se hizo lo mismo con respecto a los progenitores, esto es difundir el cuestionario entre madres y padres que tuviesen hijos cursando dichas etapas. 
En cualquier caso, se es consciente de que la transformación del sistema educativo a partir de la pandemia del coronavirus ha sido más drástica para la docencia en etapas como Primaria, donde la presencialidad del sistema educativo se hace más necesaria. Aunque en menor grado, también Secundaria y Bachillerato se han visto bastante afectados, en especial los alumnos que titulan. Especial mención para los discentes de segundo de Bachillerato, cuyos cambios les ha generado mayor incertidumbre si cabe en un curso de por sí difícil como es el previo a la Universidad. Por otro lado, la etapa educativa que menos se ha visto frenada en el avance de contenidos ha sido el propio ámbito universitario. Un hecho que se debe, aparte de por las características intrínsecas de su alumnado, con una mayor madurez, a que buena parte de los grados y postgrados que ofrece el sistema universitario español goza de una importante y progresiva docencia online.

Todo este análisis parte de la cautela, puesto que todavía se está muy condicionado por el impacto del cambio repentino sucedido hace unos meses en el sistema educativo. Posiblemente haya que reflexionar sobre todas estas cuestiones planteadas como resultados cuando pase más tiempo. Aunque muchas de las conclusiones extraídas pueden servir ya para marcar el camino a seguir y contribuir a readaptar algunas de las propuestas didácticas geográficas a las necesidades del sistema educativo actual, donde la no presencialidad ganará protagonismo en comparación a los cursos pasados. En especial, con la gran probabilidad de volver a una situación similar para el próximo curso. Estudios recientes como el de Cotino Hueso (2020) también inciden en aprovechar los cambios sufridos en el sistema educativo para plantearse reformas que ayuden a mejorarlo.

Como se verá en las tablas de datos, uno de los rasgos que los tres grupos de la comunidad educativa destacan es el carácter práctico que tiene el saber geográfico. De hecho, con el confinamiento, al no haber clases presenciales, se han dejado sin realizar infinidad de ejercicios prácticos (de laboratorio, salidas de campo...) Incluso en algunos de los formularios del profesorado se deja constancia de que la parte práctica debería tener una mayor importancia en las propias programaciones didácticas. Esta percepción recogida de los cuestionarios realizados enlaza con la comparativa que De Miguel (2012) hizo entre varios países europeos. En ese estudio se comprobó cómo el currículo educativo de nuestro país otorga un menor protagonismo que el conjunto de países comparados en cuanto a la importancia de itinerarios o salidas de campo, respecto al aprendizaje por descubrimiento o el análisis entre espacios geográficos, entre otras metodologías más experienciales. En definitiva, el proceso de enseñanzaaprendizaje de la geografía debe considerarse como un saber más práctico, donde los conocimientos pueden ser adquiridos por el alumnado por descubrimiento o, por ejemplo, por comparación entre territorios o paisajes.

Esta y otras conclusiones son fruto de los resultados recopilados gracias a las aproximadamente 550 encuestas realizadas voluntariamente y que representan el conjunto 
de sujetos que forman la comunidad educativa vinculada a la disciplina geográfica y dentro de los niveles de Secundaria, Bachillerato y Universidad.

A continuación, se procede a explicar las principales características de cada uno de los tres grupos que forman parte de la propia comunidad educativa: profesorado, alumnado y progenitores.

\subsection{Características de los grupos que componen la muestra de estudio}

Respecto al número de cuestionarios cumplimentado por el alumnado, este ha sido de 260, una cifra muy similar al del profesorado. Estas encuestas son todas válidas por haberse descartado previamente aquellas que, como se ha explicado en el apartado metodológico, pudiesen resultar fraudulentas. La distribución por sexos ha sido muy similar; del conjunto de alumnos que han respondido, el $45 \%$ han sido mujeres y el 55\% hombres. Según el nivel de estudios, del total de ellos, un poco más de la mitad de las muestras (51\%) corresponden a estudiantes de Secundaria, el 25\% se encuentra cursando bachillerato y el $24 \%$ son universitarios. De todos ellos, el $75 \%$ están matriculados en centros educativos públicos, una cuarta parte en centros concertados y no hay representación de los centros privados a pesar de haber dirigido el cuestionario de igual manera a los colegios y universidades privadas. El alumnado pertenece a 6 universidades y 26 centros de secundaria de distintas regiones de España.

Igual que para el colectivo anterior, para conocer la situación del profesorado la encuesta fue dirigida especialmente a los centros educativos de secundaria y universidad. En concreto 247 docentes han realizado de manera voluntaria y anónima el formulario.

La mayoría de las encuestas han sido realizadas por hombres (58\%), mientras que las mujeres representan el $42 \%$, al contrario de lo que sucede en el sondeo realizado con los alumnos o los progenitores. Los dos grupos de edad más representativos en el profesorado son de 35 a 50 años (41\%) y de 50 a $65(46 \%)$. El 12\% tiene una edad comprendida entre los 22 y 35 años y el $2 \%$ restante más de 65 . El nivel educativo en el que imparten clase los profesores que han realizado el cuestionario es mayoritariamente en secundaria (44\%), en bachillerato (33\%) y en universidad (23\%). El $87 \%$ de los docentes pertenecen a centros públicos, un $12 \%$ a concertados y un $1 \%$ a privados. Es el único dato que se ha recogido de centros privados y responde a un profesor de un instituto y dos de universidad. En este sentido, debe decirse que el sondeo se hizo llegar por igual a todos los centros al margen de su titularidad, pero, aun sabiendo que el número de instituciones es mayoritariamente público, se esperaba haber tenido una mayor representación de la educación privada.

Las encuestas del profesorado de estudios superiores provienen de 16 campus públicos y 1 privado, mientras que los docentes de centros de secundaria corresponden 
a 104 institutos diferentes. Con todo ello se ha obtenido una cierta representatividad geográfica del país al tener datos de 39 de las 50 provincias españolas.

Para el colectivo de progenitores la muestra recogida ha sido considerablemente inferior, con cuarenta formularios. Aunque pocas, estas han sido geográficamente muy bien distribuidas, al proceder de doce provincias distintas. Tal vez, uno de los datos que más sorprende de los extraídos del sondeo realizado a los progenitores o tutores legales es que de las encuestas, el $95 \%$ corresponden a madres. Un contraste muy marcado que evidencia el desigual reparto de tareas por sexo en cuanto al interés por el seguimiento docente de los hijos. La mayor parte de las madres (44\%) que han respondido tienen a sus hijos cursando bachillerato, con porcentajes en torno al $25 \%$, a partes iguales, en primaria y secundaria y el $6 \%$ tiene hijos universitarios. De nuevo se repite el predominio de los centros públicos $(88 \%)$ frente a los concertados, manteniéndose el hermetismo de los centros educativos privados.

\subsection{Análisis y resultados de los cuestionarios cumplimentados}

A continuación, se expone la mayor parte de los ítems planteados y que forman cada cuestionario. Cada una de las tablas de datos presentada muestra el grado de agrado o desagrado de cada colectivo encuestado. Para cada pregunta se podía contestar en una escala de cinco valores que comprendía entre el nada o muy poco de acuerdo y el mucho o muy de acuerdo, pero que ha sido sintetizada en su presentación como se muestra.

Ante la limitación de la extensión del artículo se han reducido las conclusiones extraídas, sobre todo aquellas aportadas en los espacios dejados para que cada sujeto pudiese sugerir cualquier opinión o aportación en aquellas preguntas con respuesta abierta y que recogen muchas preocupaciones y experiencias vividas por todos los miembros de la comunidad educativa.

\begin{tabular}{|c|c|c|c|c|c|c|}
\hline & \multicolumn{2}{|c|}{ Profesorado (\%) } & \multicolumn{2}{|c|}{ Alumnado (\%) } & \multicolumn{2}{|c|}{$\begin{array}{c}\text { Madres y padres } \\
(\%)\end{array}$} \\
\hline & $\begin{array}{l}\text { Nada } \\
\text { / Muy } \\
\text { poco }\end{array}$ & $\begin{array}{l}\text { Algo / } \\
\text { Mucho }\end{array}$ & $\begin{array}{l}\text { Nada } \\
\text { / Muy } \\
\text { poco }\end{array}$ & $\begin{array}{l}\text { Algo / } \\
\text { Mucho }\end{array}$ & $\begin{array}{l}\text { Nada } \\
\text { / Muy } \\
\text { poco }\end{array}$ & $\begin{array}{l}\text { Algo / } \\
\text { Mucho }\end{array}$ \\
\hline Inicialmente angustia & 36,3 & 53,5 & 28,1 & 57,1 & 17,5 & 77,5 \\
\hline Inicialmente tranquilidad & 48,2 & 36,9 & 47,2 & 31,6 & 60 & 30 \\
\hline $\begin{array}{l}\text { De manera generalizada } \\
\text { angustia }\end{array}$ & 53,5 & 38,5 & 34,1 & 47,1 & 22,5 & 70 \\
\hline $\begin{array}{l}\text { Una vez dominada la } \\
\text { situación, tranquilidad }\end{array}$ & 13,5 & 64,6 & 22,4 & 56,1 & 20 & 67,5 \\
\hline
\end{tabular}




\begin{tabular}{|c|c|c|c|c|c|c|}
\hline & \multicolumn{2}{|c|}{ Profesorado (\%) } & \multicolumn{2}{|c|}{ Alumnado (\%) } & \multicolumn{2}{|c|}{$\begin{array}{c}\text { Madres y padres } \\
(\%)\end{array}$} \\
\hline & $\begin{array}{l}\text { Nada } \\
\text { / Muy } \\
\text { poco }\end{array}$ & $\begin{array}{l}\text { Algo / } \\
\text { Mucho }\end{array}$ & $\begin{array}{l}\text { Nada } \\
\text { / Muy } \\
\text { poco }\end{array}$ & $\begin{array}{l}\text { Algo / } \\
\text { Mucho }\end{array}$ & $\begin{array}{l}\text { Nada } \\
\text { / Muy } \\
\text { poco }\end{array}$ & $\begin{array}{l}\text { Algo / } \\
\text { Mucho }\end{array}$ \\
\hline $\begin{array}{l}\text { Me ha resultado } \\
\text { complicado }\end{array}$ & 29,4 & 59,2 & 28,1 & 54 & - & - \\
\hline $\begin{array}{l}\text { Me ha generado trabajo } \\
\text { extra }\end{array}$ & 4,5 & 91,9 & 13,7 & 77,1 & 15 & 80 \\
\hline $\begin{array}{l}\text { Ha provocado situaciones } \\
\text { de estrés añadido }\end{array}$ & 15,9 & 73,1 & 28,9 & 61,2 & 20 & 80 \\
\hline $\begin{array}{l}\text { Por lo general, he tenido } \\
\text { dificultades }\end{array}$ & 31 & 49,8 & 50,6 & 30,4 & 52,5 & 45 \\
\hline $\begin{array}{l}\text { He conseguido ver el lado } \\
\text { positivo y me agrada }\end{array}$ & 30,6 & 52,3 & 27 & 52,9 & - & - \\
\hline $\begin{array}{l}\text { He contado con el apoyo } \\
\text { de compañeros que me } \\
\text { han ayudado }\end{array}$ & - & - & 16,7 & 66,2 & - & - \\
\hline $\begin{array}{l}\text { A los hijos les ha resultado } \\
\text { complicado }\end{array}$ & - & - & - & - & 20 & 80 \\
\hline $\begin{array}{l}\text { Como padres hemos } \\
\text { estado muy apoyados por } \\
\text { los profesores }\end{array}$ & - & - & - & - & 40 & 57,5 \\
\hline $\begin{array}{l}\text { He notado mejoría en el } \\
\text { rendimiento de mi hijo/a }\end{array}$ & - & - & - & - & 42,5 & 35 \\
\hline
\end{tabular}

TABLA 1. Grado de acuerdo (en porcentaje) de cada colectivo de la comunidad educativa respecto a la situación que se ha atravesado con la trasformación de una educación presencial a digital a partir de la propagación de la COVID-19 en marzo de 2020.

Fuente: Elaboración propia

La Tabla 1 recoge ciertas consecuencias derivadas de la transformación de una educación presencial a una a distancia durante los primeros meses de su transformación, donde la sensación de angustia y agobio era común en la mayor parte de la comunidad educativa. Los resultados reflejan que el colectivo que mayor angustia padeció con el confinamiento fueron los progenitores, aunque los tres grupos confirman haber vivido situaciones de estrés adicional ante la situación de crisis sanitaria. De hecho, la práctica totalidad de los docentes (92\%) afirman haber tenido trabajo extra como es de esperar en una situación inesperada. Lo importante sería aprender de dicha experiencia para futuras ocasiones. Más de la mitad del alumnado confirma haber contado con la ayuda de compañeros. Para 
una mayoría de madres y padres (80\%), sus hijos, especialmente los matriculados en Secundaria y Bachillerato tuvieron complicaciones con el cambio drástico del sistema. Más de la mitad de los progenitores sintieron el apoyo de los docentes. Este colectivo no aprecia una clara mejoría en el rendimiento de los hijos con el cambio.

La Tabla 2 recoge la percepción que cada uno de los colectivos entrevistados tiene sobre ellos mismos. Así, casi la totalidad de los docentes (97\%) afirman haberlo dado todo durante los primeros meses de cambio. Un porcentaje que se mantiene también alto según los otros dos colectivos. De igual manera los tres grupos son comprensibles con el sobreesfuerzo realizado por el alumnado. De forma parecida, los progenitores tienen una altísima sensación $(82,5 \%)$ de haberse esforzado al máximo. Por el contrario, la administración y los servicios educativos no están tan bien valorados, aunque los que están considerados de manera muy negativa son los responsables políticos con cargos en educación. Muchas opiniones recogidas por docentes apuntan en esta dirección como uno de los problemas fundamentales del sistema educativo español. Algunas de las aportaciones registradas aluden a la falta de dirigentes en educación suficientemente competentes, más allá de su escala de actuación. Se critica la falta de voluntad comprometida de los políticos por conocer y mejorar la situación real por la que pasa el sistema educativo, a excepción de medidas concretas como, en algunos casos, la disposición de aparatos electrónicos para reducir la brecha digital. Los datos reflejan este descontento, que es especialmente patente en el profesorado, con un $84 \%$ del mismo solicitando una mayor involucración por parte de la gestión política.

\begin{tabular}{lcccccc}
\hline & \multicolumn{2}{c}{ Profesorado (\%) } & \multicolumn{2}{c}{ Alumnado (\%) } & \multicolumn{2}{c}{ Madres y padres (\%) } \\
\cline { 2 - 7 } & $\begin{array}{c}\text { Muy poco / } \\
\text { Poco }\end{array}$ & $\begin{array}{c}\text { Algo / } \\
\text { Mucho }\end{array}$ & $\begin{array}{c}\text { Muy poco / } \\
\text { Poco }\end{array}$ & $\begin{array}{c}\text { Algo / } \\
\text { Mucho }\end{array}$ & $\begin{array}{c}\text { Muy poco } \\
\text { / Poco }\end{array}$ & $\begin{array}{c}\text { Algo / } \\
\text { Mucho }\end{array}$ \\
\hline $\begin{array}{l}\text { Los profesores lo } \\
\text { están dando todo }\end{array}$ & 1,2 & 96,7 & 16 & 66,5 & 12,5 & 72,5 \\
$\begin{array}{l}\text { Los alumnos lo están } \\
\text { dando todo }\end{array}$ & 12 & 80,2 & 8,9 & 74,5 & 20 & 75 \\
$\begin{array}{l}\text { El profesorado podría } \\
\text { dar más de sí }\end{array}$ & 53,1 & 30,6 & 29,6 & 52,8 & 30 & 57,5 \\
$\begin{array}{l}\text { El alumnado podría } \\
\text { dar más de si }\end{array}$ & 23,1 & 62 & 20,1 & 57,8 & 30 & 52,5 \\
$\begin{array}{l}\text { Los padres o tutores } \\
\text { legales (para alumnos } \\
\text { menores de edad) lo } \\
\text { están dando todo. }\end{array}$ & 9,5 & 57,3 & 6,8 & 63,5 & 5 & 82,5 \\
\hline
\end{tabular}




\begin{tabular}{lcccccc}
\hline & \multicolumn{2}{c}{ Profesorado (\%) } & \multicolumn{2}{c}{ Alumnado (\%) } & \multicolumn{2}{c}{ Madres y padres (\%) } \\
\cline { 2 - 7 } & $\begin{array}{c}\text { Muy poco / } \\
\text { Poco }\end{array}$ & $\begin{array}{c}\text { Algo / } \\
\text { Mucho }\end{array}$ & $\begin{array}{c}\text { Muy poco / } \\
\text { Poco }\end{array}$ & $\begin{array}{c}\text { Algo / } \\
\text { Mucho }\end{array}$ & $\begin{array}{c}\text { Muy poco } \\
\text { / Poco }\end{array}$ & $\begin{array}{c}\text { Algo / } \\
\text { Mucho }\end{array}$ \\
\hline $\begin{array}{l}\text { La administración y } \\
\text { servicios educativos } \\
\text { lo está dando todo }\end{array}$ & 47,3 & 39,5 & 22,8 & 52,9 & 42,5 & 40 \\
$\begin{array}{l}\text { Los representantes } \\
\text { políticos con cargos } \\
\text { en educación lo están } \\
\text { dando todo }\end{array}$ & 70,1 & 15,4 & 41,4 & 35,4 & 67,5 & 12,5 \\
$\begin{array}{l}\text { Los representantes } \\
\text { políticos con cargos } \\
\text { en educación } \\
\text { deberían involucrarse } \\
\text { más }\end{array}$ & 8,3 & 84,6 & - & & & \\
\hline
\end{tabular}

TABLA 2. Grado de conformidad (en porcentaje) de cada colectivo de la comunidad educativa sobre ellos mismos. Fuente: Elaboración propia

Las siguientes tablas estadísticas (Tablas 4, 5 y 6) muestran el papel de la Geografía, según profesores y alumnos, dada la situación actual generada a partir del cambio a un sistema de enseñanza-aprendizaje a distancia. Respecto a estas cuestiones también se tienen datos del colectivo de madres y padres que, por sintetizar, no se muestran, aunque la mayoría de sus cuestionarios resalta el eminente carácter práctico de la Geografía y la importancia de esta para que sus hijos comprendan mejor el mundo en el que viven.

Destaca la apreciación fundamental que, para el conjunto de profesores y alumnos, tiene la Geografía como saber práctico. Ambos colectivos consideran que existen suficientes recursos digitales para enseñar y aprender Geografía, si bien quizás ponen el punto de atención en el excesivo número de programas y herramientas y solicitan canalizar y homogeneizar metodologías en este sentido. Para ello, la administración pública y organismos internacionales como la UNESCO (2020 b) han lanzado listados muy completos con herramientas y recursos digitales de lo más variado para ayudar a solventar esta cuestión, aunque el hecho de disponer de tantos listados de herramientas se torna al revés y pasa a convertirse en problema.

Profesores y discentes están de acuerdo en afirmar que, aunque ha cambiado la metodología, no se han modificado los contenidos finales y que los recursos digitales no sustituyen a las actividades geográficas presenciales (salidas de campo, itinerarios didácticos, trabajo de laboratorio...). De hecho, se piensa que la mejor manera de adquirir conocimiento geográfico es in situ, por lo que la Geografía difícilmente saldrá fortalecida de esta situación de educación a distancia. Un hecho que obligaría a replantearse el 
sistema de enseñanza-aprendizaje más profunda de como se ha hecho en las últimas décadas y que pudiese encaminarse hacia un mayor aprendizaje fuera de las aulas o 'outdoor learning'.

\begin{tabular}{|c|c|c|c|c|c|c|}
\hline & \multicolumn{3}{|c|}{ Profesorado (\%) } & \multicolumn{3}{|c|}{ Alumnado (\%) } \\
\hline & $\begin{array}{c}\text { Nada / } \\
\text { Muy poco }\end{array}$ & Igual & $\begin{array}{l}\text { Algo / Muy } \\
\text { de acuerdo }\end{array}$ & $\begin{array}{c}\text { Nada / } \\
\text { Muy poco }\end{array}$ & Igual & $\begin{array}{l}\text { Algo / Muy } \\
\text { de acuerdo }\end{array}$ \\
\hline $\begin{array}{l}\text { La trasmisión de } \\
\text { conocimientos ha } \\
\text { cambiado en el medio o } \\
\text { en las formas, pero no en } \\
\text { el contenido final }\end{array}$ & 14,7 & 9,4 & 75,9 & 20,9 & 27,4 & 51,7 \\
\hline $\begin{array}{l}\text { Existen suficientes } \\
\text { recursos digitales } \\
\text { para enseñar/aprender } \\
\text { Geografía a distancia }\end{array}$ & 18 & 13,9 & 68,2 & 14,1 & 20,2 & 65,8 \\
\hline $\begin{array}{l}\text { Considero que existen } \\
\text { demasiados recursos } \\
\text { digitales para afrontar la } \\
\text { Geografía. De hecho, me } \\
\text { resulta complicado elegir }\end{array}$ & 43,3 & 26,5 & 30,2 & 41,5 & 28,5 & 30 \\
\hline $\begin{array}{l}\text { Las actuales herramientas } \\
\text { y recursos digitales } \\
\text { sustituyen por completo } \\
\text { a las tradicionales } \\
\text { actividades presenciales }\end{array}$ & 82 & 6,9 & 10,6 & - & - & - \\
\hline $\begin{array}{l}\text { La Geografía es una } \\
\text { materia que contribuye a } \\
\text { enseñar el paisaje próximo } \\
\text { o el propio entorno de los } \\
\text { alumnos. Con la docencia } \\
\text { a distancia esto se pierde }\end{array}$ & 13,1 & 10,2 & 76,7 & 13,3 & 25,1 & 61,6 \\
\hline $\begin{array}{l}\text { La mejor manera de } \\
\text { enseñar y aprender } \\
\text { conocimientos geográficos } \\
\text { ha sido siempre, es y será } \\
\text { estando in situ (sobre el } \\
\text { propio territorio) }\end{array}$ & 9,3 & 10,6 & 80 & 10,3 & 26,6 & 63,1 \\
\hline $\begin{array}{l}\text { La Geografía puede salir } \\
\text { fortalecida con la docencia } \\
\text { a distancia }\end{array}$ & 47,7 & 31,4 & 20,8 & 47,6 & 32,7 & 19,8 \\
\hline
\end{tabular}




\begin{tabular}{lcccccc}
\hline & \multicolumn{3}{c}{ Profesorado (\%) } & & Alumnado (\%) \\
\cline { 2 - 7 } & $\begin{array}{c}\text { Nada / } \\
\text { Muy poco }\end{array}$ & Igual & $\begin{array}{c}\text { Algo / Muy } \\
\text { de acuerdo }\end{array}$ & $\begin{array}{c}\text { Nada / } \\
\text { Muy poco }\end{array}$ & Igual & $\begin{array}{c}\text { Algo / Muy } \\
\text { de acuerdo }\end{array}$ \\
\hline $\begin{array}{l}\text { Muchas de las dinámicas } \\
\text { o actividades de Geografía } \\
\text { que estaban organizadas } \\
\text { para estos meses, no han } \\
\text { podido llevarse a cabo con } \\
\text { la docencia a distancia }\end{array}$ & 15,5 & 10,6 & 73,8 & 20,1 & 23,2 & 56,7 \\
$\begin{array}{l}\text { Estas iniciativas que no } \\
\text { se han podido realizar han } \\
\text { sido sustituidas por unas } \\
\text { similares }\end{array}$ & 53,9 & 16,3 & 29,8 & 46,4 & 25,5 & 28,1 \\
$\begin{array}{l}\text { El tipo de propuestas que } \\
\text { estaban organizadas no } \\
\text { pueden ser sustituidas con } \\
\text { los medios digitales }\end{array}$ & 23,3 & 18,4 & & & & \\
\hline
\end{tabular}

TABLA 3. Grado de acuerdo (en porcentaje) de docentes y discentes con respecto a las transformaciones que se han producido y que afectan al campo de la Geografía al pasar de un sistema educativo presencial a digital. Fuente: Elaboración propia

Como muestra la Tabla 4, el profesorado es crítico consigo mismo al considerar que no está bien formado para el sistema educativo no presencial, una característica que el alumnado general no aprecia, aunque, si se hace distinción entre alumnos, los universitarios sí son más críticos en este sentido.

Se vuelve a destacar el valor del saber geográfico como aprendizaje vivencial y experimental, algo que se dificulta con la reducción de la movilidad y del distanciamiento social como medidas para frenar la pandemia del coronavirus.

\begin{tabular}{lcccccc}
\hline & \multicolumn{3}{c}{ Profesorado (\%) } & \multicolumn{2}{c}{ Alumnado (\%) } \\
\cline { 2 - 7 } & $\begin{array}{c}\text { Nada / Igual } \\
\text { Muy poco }\end{array}$ & $\begin{array}{c}\text { Algo / } \\
\text { Muy de } \\
\text { acuerdo }\end{array}$ & $\begin{array}{c}\text { Nada / } \\
\text { Muy poco }\end{array}$ & Igual & $\begin{array}{c}\text { Algo / } \\
\text { Muy de } \\
\text { acuerdo }\end{array}$ \\
\hline $\begin{array}{l}\text { Los profesores de Geografía no } \\
\text { estaban bien formados para el } \\
\text { sistema educativo a distancia }\end{array}$ & 22 & 19,6 & 58,4 & 47,6 & 25,5 & 27 \\
$\begin{array}{l}\text { Cuando la crisis sanitaria } \\
\text { pase, volveremos a llevar a la } \\
\text { práctica dinámicas o actividades } \\
\text { presenciales }\end{array}$ & 2 & 12,2 & 85,7 & 13,3 & 28,1 & 58,6 \\
\hline
\end{tabular}




\begin{tabular}{|c|c|c|c|c|c|c|}
\hline & \multicolumn{3}{|c|}{ Profesorado (\%) } & \multicolumn{3}{|c|}{ Alumnado (\%) } \\
\hline & $\begin{array}{c}\text { Nada / } \\
\text { Muy poco }\end{array}$ & Igual & $\begin{array}{l}\text { Algo / } \\
\text { Muy de } \\
\text { acuerdo }\end{array}$ & $\begin{array}{c}\text { Nada / } \\
\text { Muy poco }\end{array}$ & Igual & $\begin{array}{l}\text { Algo / } \\
\text { Muy de } \\
\text { acuerdo }\end{array}$ \\
\hline $\begin{array}{l}\text { Considero muy importante } \\
\text { realizar ejercicios prácticos } \\
\text { presenciales en Geografía }\end{array}$ & 1,2 & 24,1 & 92,3 & 8,4 & 24,7 & 66,9 \\
\hline $\begin{array}{l}\text { Las actuales herramientas y } \\
\text { recursos digitales sustituyen } \\
\text { por completo a las tradicionales } \\
\text { actividades presenciales }\end{array}$ & - & - & - & 45,2 & 27,8 & 27 \\
\hline $\begin{array}{l}\text { La actual educación a distancia } \\
\text { me ha hecho valorar más } \\
\text { la importancia que tiene } \\
\text { la Geografía para conocer, } \\
\text { contactar y "sentir" el espacio/ } \\
\text { paisaje }\end{array}$ & 8,6 & 26,1 & 65,3 & 17,4 & 33,5 & 49,1 \\
\hline $\begin{array}{l}\text { No ha sido necesario la } \\
\text { situación actual de alarma para } \\
\text { darme cuenta que la Geografía } \\
\text { como mejor se aprende es in } \\
\text { situ }\end{array}$ & 8,6 & 20,4 & 71 & 20,9 & 31,9 & 47,1 \\
\hline
\end{tabular}

TABla 4. Grado de conformidad o disconformidad (en porcentaje) de profesores y estudiantes con respecto a cambios específicos en el ámbito del conocimiento geográfico al pasar de una educación presencial a digital. Fuente: elaboración propia

La Tabla 5 alude a cuestiones más específicas sobre Sistemas de Información Geográfica y ha sido completado por aquel conjunto de profesores y alumnos universitarios que respondiesen previamente y de manera positiva a la cuestión ¿sabes qué es un SIG?

Del total del alumnado, un $70 \%$ no sabe qué es un SIG. Este dato puede hacer reflexionar sobre una posible falta de incorporación de herramientas digitales a las aulas de los niveles preuniversitarios o, por otro lado, se trabaja pero los estudiantes no lo relacionan con dicho concepto. Los alumnos que han respondido consideran en su mayoría (44\%) que los ejercicios fundamentados en SIG han tenido que cambiar con el paso a la educación online y que, incluso, se han tenido que incluir alguna actividad más de este tipo, aunque parte del trabajo con estas herramientas se frenó por necesitar formación presencial previa.

Casi la mitad del profesorado considera que los sistemas de información geográfica se han visto fortalecidos con la educación digital, aunque han tenido que cambiar las prácticas entre otros motivos porque se necesitaba enseñanza previa para su formación. Más del 
58\% de los docentes afirman no estar lo suficientemente preparados para el uso de SIGs. A este respecto para la mejora de la enseñanza y el aprendizaje de SIGs existen manuales de carácter práctico donde se describe el tratamiento de este tipo de herramientas digitales en función del nivel de conocimientos del alumnado o los distintos grados de utilización de los datos geográficos (Andrades et al. 2020).

\begin{tabular}{|c|c|c|c|c|c|c|}
\hline & \multicolumn{3}{|c|}{ Profesorado (\%) } & \multicolumn{3}{|c|}{ Alumnado (\%) } \\
\hline & $\begin{array}{c}\text { Nada / } \\
\text { Muy poco }\end{array}$ & Igual & $\begin{array}{l}\text { Algo / } \\
\text { Muy de } \\
\text { acuerdo }\end{array}$ & $\begin{array}{l}\text { Nada / Muy } \\
\text { poco }\end{array}$ & Igual & $\begin{array}{l}\text { Algo / Muy } \\
\text { de acuerdo }\end{array}$ \\
\hline $\begin{array}{l}\text { Los SIG se han visto } \\
\text { fortalecidos con la docencia } \\
\text { a distancia }\end{array}$ & 22,2 & 29 & 48,8 & 33,3 & 31 & 35,7 \\
\hline $\begin{array}{l}\text { Las prácticas que utilizan } \\
\text { SIGs han tenido que cambiar }\end{array}$ & 20,2 & 32,5 & 47,3 & 20,2 & 35,7 & 44 \\
\hline $\begin{array}{l}\text { El profesorado se ha visto } \\
\text { obligado a incluir más } \\
\text { ejercicios con SIG con la } \\
\text { educación a distancia }\end{array}$ & 19,5 & 39 & 41,5 & 22,6 & 33,3 & 44 \\
\hline $\begin{array}{l}\text { Incluso tareas con SIGs se } \\
\text { han visto frenadas con la } \\
\text { docencia a distancia puesto } \\
\text { que necesitaban de una } \\
\text { formación presencial previa } \\
\text { del alumnado }\end{array}$ & 20,3 & 27,7 & 52 & 27,4 & 32,1 & 40,5 \\
\hline $\begin{array}{l}\text { La formación a distancia } \\
\text { refleja que la mayoría de } \\
\text { los profesores no están } \\
\text { preparados para el uso de } \\
\text { SIGs }\end{array}$ & 11,5 & 30 & 58,5 & 34,6 & 35,7 & 29,7 \\
\hline
\end{tabular}

TABLA 5. Grado de acuerdo (en porcentaje) del profesorado y el alumnado con respecto a las transformaciones que la enseñanza-aprendizaje de SIG haya podido sufrir con el cambio del sistema educativo. Fuente: elaboración propia

Entre las demandas más solicitadas por el alumnado en base al tipo de docencia que tuvieron durante los meses de confinamiento se encuentran: un mayor número de clases por videoconferencia, mayor formación en herramientas informáticas, profesorado más ágil con las telecomunicaciones y una homogeneización que evite múltiples plataformas. Desde el punto de vista del colectivo de docentes destaca la falta de formación digital que permita un eficiente seguimiento de los discentes y la ausencia de readaptación al sistema online, lo que ha generado trabajo extra y ha roto los límites de la jornada laboral. 
También se echa de menos una mayor autonomía informática del alumnado, sobre todo en niveles preuniversitarios. El tercer grupo que forma la comunidad educativa, el de madres y padres, recalcan la dificultad de ayudar a sus hijos en los primeros momentos, pues se ven faltos de conocimientos para colaborar en el aprendizaje a distancia de sus hijos y, evidentemente, muchos de ellos destacan la dificultad de compatibilizar la vida laboral y familiar desde los mismos hogares.

Los tres grupos han reconocido el esfuerzo y la implicación realizada por cada uno de ellos. Y tanto estudiantes como profesores han señalado los esfuerzos realizados por la administración para reducir la brecha digital, aunque son conscientes de que, en caso de seguir un sistema educativo semipresencial de manera prolongada y no solo el último trimestre del pasado curso, el problema se acentuaría considerablemente.

\section{CONCLUSIONES}

La capacidad de propagación del virus más letal en lo que llevamos de siglo XXI hizo que la vida entrase en una pausa incierta al confinar a la mayor parte del planeta durante el primer semestre del año 2020. Las calles del mundo se vaciaron a medida que el brote sumaba víctimas. 4.500 millones de personas de más de 180 países permanecieron retenidos en sus casas. Buena parte de la actividad económica quedó suspendida. El aislamiento de la sociedad se convirtió en el único antídoto posible contra el enemigo a batir. Y todo esto tuvo una consecuencia directa en el sistema de enseñanza-aprendizaje, que tuvo que pasar de presencial a distancia de manera drástica. La permanencia de la COVID-19 hasta que la comunidad científica no consiga detenerlo plantea numerosas cuestiones y retos en cualquier ámbito de nuestras vidas, incluido el propio sistema educativo. La pregunta será si esto tendrá retorno o no. Confiemos en que la normalidad se instaure poco a poco y se pueda volver a la presencialidad, pero lo que sí está claro es que la utilización de las telecomunicaciones en el sistema de enseñanza-aprendizaje será más intenso y continuo.

Por otro lado, a lo largo de las últimas décadas, la escuela ha ido asumiendo el rol que, tiempos atrás, era más propio de los hogares o familias, sobre la responsabilidad de convertir al alumnado en personas respetuosas y cívicas. Queda patente que, aunque los padres y madres tienen una gran responsabilidad en la educación de sus hijos e hijas en lo que a socialización se refiere, también lo tiene el propio sistema educativo. Es decir, el sistema escolar se postula como un actor principal en cuanto a enseñar y transmitir modelos de convivencia o valores éticos y morales, a nivel de sociedad. Los centros educativos, al menos en las etapas previas a la Universidad, se postulan como auténticos responsables y representantes de la formación ciudadana. Un hecho que incluso en el ámbito universitario también se aprecia cada vez más. Todo esto se ha 
puesto más de manifiesto, si cabe, cuando los alumnos, igual que el resto de la sociedad, han permanecido confinados en casa durante semanas y, por lo tanto, conviviendo de manera obligada con sus familias.

Materias como la Geografía, como ciencia social que es, puede y tiene mucho que aportar en toda esta situación. Quizás, incluso, la actual crisis por la COVID-19 sea una buena oportunidad para hacerse notar y demostrar su valía, dada su implicación a la hora de comprender muchos de los fenómenos y acontecimientos de la actualidad en cualquier parte del planeta. Para alcanzar dicho objetivo se puede partir del conocimiento de la situación actual que está atravesando la comunidad educativa española de manera general y en lo que a Geografía se refiere. De este modo, se puede conocer sus fortalezas y debilidades, así como las demandas de los distintos colectivos, tal y como se plantea en este trabajo.

Más allá de las dificultades encontradas, del estrés y las situaciones de tensión o de angustia generadas en un primer momento, los resultados presentados sirven para ayudar a replantearse determinadas cuestiones de trasfondo, como las estrategias para impartir el contenido teórico, el conjunto de herramientas informáticas más adecuadas para cada nivel y para cada situación concreta. Ante una situación como la actual, donde el carácter práctico de la Geografía se ve frenado, se debe conseguir llegar al alumnado y despertar en él el interés por el saber geográfico mediante otros procedimientos. El desarrollo de un aprendizaje significativo y constructivista contribuye a ello. Así, un aprendizaje por descubrimiento sirve a los alumnos para tener un papel activo y sentirse parte fundamental de su aprendizaje, lo que despierta su motivación. Si todo ello se consigue a través del conocimiento geográfico, como medio y fin para comprender mejor la realidad en la que vive, crear conciencia social y medioambiental, se estará contribuyendo de este modo a formar adecuadamente a personas cívicas.

El paso del tiempo confirmará o no si la actual crisis sanitaria generada por el coronavirus es una situación excepcional, puesto que el desconocimiento del virus genera incertidumbre con respecto al futuro más próximo en cualquier ámbito que se analice. El sistema educativo, como se ha visto, no es ajeno a ello y ha sido muy afectado. En estos momentos se debaten las medidas y estrategias a desarrollar ante la denominada 'nueva normalidad'. La manera en la que se ha vuelto a las aulas se ha realizado, en la mayoría de los casos, de manera precipitada y sin demasiado consenso al haber desaprovechado los meses de verano. Para los niveles de primaria se ha apostado por la presencialidad, incluso para la secundaria, aunque en aquellos casos en los que no se aseguraba la distancia de metro y medio entre alumnos se ha optado por desdoblar grupos, por la semipresencialidad combinado días alternos, etc. Y en el caso de la Universidad todavía ha sido más variado, al comprender desde la apuesta por la presencialidad máxima, siempre que las medidas sanitarias lo permitan, a la docencia plenamente a distancia. 
La falta de criterios comunes acentuará todavía más las diferencias de preparación entre alumnos con niveles similares entre las distintas regiones o campus universitarios. Todo esto hace que se esté en un momento clave en el que todos los miembros del sistema educativo deben plantear sus posiciones para alcanzar el mejor entendimiento.

Por todo ello, la comunidad educativa debe prepararse ante el reto de cómo adaptarse a una posible educación semipresencial o digital a medio y largo plazo. Su mayor o menor grado de adecuación a dicha situación marcará el resultado final exitoso o no del sistema de enseñanza-aprendizaje. Esto no justifica que la toma de decisiones tenga que partir del oportunismo al que, con frecuencia, se recurre a partir de situaciones desconcertantes como la actual para cambiar cuestiones de manera drástica y sin el suficiente debate o acuerdo común. La presentación de los resultados de este trabajo pretende dar a conocer las inquietudes y las consecuencias que se han podido generar entre los principales integrantes de la comunidad educativa, conocer su perspectiva con respecto a la enseñanza-aprendizaje del saber geográfico y descubrir posibles necesidades o limitaciones para tratar de avanzar en la transmisión y aprendizaje del saber geográfico, su adaptación a las transformaciones sociales, las tecnologías actuales disponibles, la formación del profesorado, etc. más allá de la crisis actual.

\section{AGRADECIMIENTOS}

Un agradecimiento expreso a todas esas personas anónimas que de manera altruista decidieron colaborar y responder al formulario en momentos difíciles, justo, cuando nuestro país todavía se encontraba prácticamente al inicio de la fase de desescalada, tras semanas de confinamiento, y coincidiendo con la recta final de curso con lo que conlleva de trabajo adicional. De la misma manera, se agradece la ayuda proporcionada en la difusión de los cuestionarios a la AGE y a su Grupo de Didáctica de la Geografía.

\section{BIBLIOGRAFÍA}

Alonso, E. (2019). Mapas Flash interactivos. Juegos didácticos para aprender Geografía Disponible en: http://serbal.pntic.mec.es/ealg0027/mapasflash.htm

Andrades, M. S., Aransay, J. M., Diago, M. P., Lana-Renault, N., Llorente, J. A., Ruiz, P. \& Sáenz de Cabezón, E. (2020). Enseñanza de Sistemas de Información Geográfica (SIG) en estudios de grado y posgrado en la Universidad de La Rioja: principios teóricos y ejercicios prácticos. Universidad de La Rioja.

Asociación Española de Geógrafos (AGE) (2020). Formulario sobre la situación actual de educación a distancia. Disponible en: https://www.age-geografia.es/site/ formulario-sobre-la-situacion-actual-de-educacion-a-distancia/ 
Cabrera, L. (2020). Efectos del coronavirus en el sistema de enseñanza: aumenta la desigualdad de oportunidades educativas en España. Revista de Sociología de la Educación - RASE, 13, 2, 114-139. http://dx.doi.org/10.7203/RASE.13.2.17125

Claudino Loureiro Nunes, S. \& Spinelli Braga, F. (2012). Educación geográfica y ciudadanía: un abordaje reflexivo. In R. De Miguel González; M. L. De Lázaro Torres; M. J. Marrón Gaite (Eds.), La educación geográfica digital. (pp. 4958). Zaragoza: Asociación de Geógrafos Españoles, Grupo de Didáctica de la Geografía y Universidad de Zaragoza.

Cotino Hueso, L. (2020). La enseñanza digital en serio y el derecho a la educación en tiempos del coronavirus. Revista de educación y derecho. Education and law review, 21, 1-29. https://doi.org/10.1344/REYD2020.21.31283

De Miguel González, R. (2012). El currículo escolar y la didáctica de la geografía en R. De Miguel González, M. L. De Lázaro Torres \& M. J. Marrón Gaite (Eds.). La educación geográfica digital. pp. 13-36). Zaragoza: Asociación de Geógrafos Españoles, Grupo de Didáctica de la Geografía y Universidad de Zaragoza.

Del Rey, R., Ortega-Ruiz, R. \& Feria, I. (2009). Convivencia escolar: fortaleza de la comunidad educativa y protección ante la conflictividad escolar. Revista Interuniversitaria de Formación de Profesorado, 23, 3, 159-180.

Jurado Gómez, C. (2009). La familia y su participación en la comunidad educativa. Revista digital de innovación y experiencias educativas, 23, Octubre, 1-10. Disponible en: https://archivos.csif.es/archivos/andalucia/ensenanza/revistas/ csicsif/revista/pdf/Numero_23/CARMEN JURADO GOMEZ01.pdf

Ministerio de Ciencia, Innovación y Universidades. (2020). QEDU, Qué Estudiar y Dónde en la Universidad. Disponible en: https://www.educacion.gob.es/centros/ home.do

Ministerio de Educación Cultura y Deporte. (2020). Registro Estatal de Centros Docentes No Universitarios (RCD) Disponible en: https://www.educacion.gob.es/centros/ home.do

Nin, M. C., Acosta, M. I. \& Leduc, S. M. (2020). Pandemia en el siglo XXI. Reflexiones de la(s) geografía(s) para su comprensión y enseñanza. Huellas, 24, 1, 219-239. http://dx.doi.org/10.19137/huellas-2020-2412

Ormazabal, M., Vadillo, V., Pontevedra, S., Arroyo, J. M. \& Bono, F. (12 marzo 2020). 9,5 millones de estudiantes se quedan dos semanas sin clase en España. El País. Disponible en: https://elpais.com/sociedad/2020-03-12/suspendidas-las-clasesen-todos-los-centros-educativos-de-euskadi.html 
Real Decreto 126/2014, de 28 de febrero, por el que se establece el currículo básico de la Educación Primaria. Boletín Oficial del Estado. n ${ }^{\circ}$ 52, de 1 de marzo de 2014, pp. 19349 a 19420 .

Real Decreto 1105/2014, de 26 de diciembre, por el que se establece el currículo básico de la Educación Secundaria Obligatoria y del Bachillerato. Boletín Oficial del

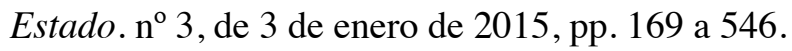

Real Decreto 463/2020, de 14 de marzo, por el que se declara el estado de alarma para la gestión de la situación de crisis sanitaria ocasionada por el COVID-19. Boletín Oficial del Estado. n ${ }^{\circ}$ 67, de 14 de marzo de 2020, pp. 25390 a 25400.

Ruiz Conesa, S. (2019). La comunicación de contenidos geográficos en el aula de secundaria. In X. C. Macía Arce; F. X. Armas Quintá; F. Rodríguez Lestegás, (Coords.), La reconfiguración del medio rural en la sociedad de la información. Nuevos desafios en la educación geográfica (pp. 421-434). Lugo: Andavira editora.

Scagnoli, N. I. (2005). Estrategias para motivar el aprendizaje colaborativo en cursos a distancia. In Ideals. Illinois Digital Environmental for Access to Learning and Scholarship. Disponible en: https://www.ideals.illinois.edu/handle/2142/10681

UNESCO. (2020 a). COVID-19 Impact on Education, In United Nations Educational, Scientific and Cultural Organization. Disponible en: https://en.unesco.org/ covid19/educationresponse

UNESCO. (2020 b). Distance learning solutions. En United Nations Educational, Scientific and Cultural Organization. Disponible en: https://en.unesco.org/ covid19/educationresponse/solutions

Zafra,I., (29 mayo 2020). Mezclar edades, reducir horario y comer en el aula: las fórmulas para que todos los alumnos vuelvan a la escuela. El país, Disponible en: https:// elpais.com/sociedad/2020-05-28/mezclar-edades-reducir-horario-y-comer-en-elaula-las-formulas-para-que-todos-los-alumnos-vuelvan-a-la-escuela.html 